\title{
Experimental Analysis on Refractory Properties of Tall Buildings
}

\author{
Ya Wang \\ Department of Architectural Engineering, Hefei University, Hefei 230601, China
}

Corresponding Author Email: yaojunaaa@qq.com

https://doi.org/10.18280/rcma.290203

Received: 18 January 2019

Accepted: 25 March 2019

\section{Keywords:}

concrete, tall building, refractory, damage evolution, damage mechanics

\begin{abstract}
High-strength concrete is commonly used in tall buildings. Due to the poor high-temperature resistance of concrete, the fire safety of tall buildings has always been a huge concern. The application of tall building refractories might slow down structural damage, reduce economic loss and protect personal safety. In this paper, the rock wool fibre was taken as an example of tall building refractories. On this basis, the author probed into the mechanical properties and damage evolution of the tall building refractory, and set up a meso-damage mechanics model for the material. The research results show that the rock wool fibre refractory (RWFR) witnessed a reduction in elastic modulus after being damaged under the growing stress; when the temperature was below $600{ }^{\circ} \mathrm{C}$, the RWFR enjoyed good properties with only a slight decline in strength, which could satisfy the requirement on the bearing capacity; the results simulated by the constitutive model agree well with the test results. The research lays solid experimental and theoretical bases for the promotion of RWFR in tall buildings.
\end{abstract}

\section{INTRODUCTION}

With the development of cities, urban land has become increasingly scarcer, and tall buildings have developed rapidly in cities. However, due to complex functions and many surrounding buildings of tall buildings, it's very difficult to control in case of fire, which will cause economic losses and even endanger personal safety [1]. As an important engineering structural material, concrete is widely used in modern architecture, transportation and other structures. At present, more than $99 \%$ of China's tall buildings have concrete structures, and the fire resistance of concrete is of great significance to the fire protection of tall buildings $[2,3]$. When a fire occurs in a tall building, heat radiation, heat convection and heat conduction are transmitted inside the concrete, which seriously deteriorates the concrete, resulting in large deformation of the member and reduced bearing capacity [4]. Developed countries such as Europe and the United States have studied refractories earlier for tall buildings. Some researchers have found that when the temperature exceeds $600{ }^{\circ} \mathrm{C}$, the strength of building concrete significantly declines, and the elastic modulus is also greatly reduced [5].

Under high temperature conditions, the strength damage of low-strength refractories is less than that of high-strength refractories. When the temperature exceeds $300{ }^{\circ} \mathrm{C}$, the strength loss of concrete materials with higher water-cement ratio is more serious [6]. In addition, the compressive strength and elasticity modulus of refractories at slow heating rates decline rapidly [7]. Currently, the properties of building refractory such as combustion performance, mechanical properties, smoke performance, toxicity performance and thermal insulation properties are mainly measured, and there are strict requirements on the quality of refractories in buildings $[8,9]$. In this paper, the rock wool fibre was taken as an example of tall building refractories. On this basis, the author probed into the mechanical properties and damage evolution of the tall building refractory, and set up a mesodamage mechanics model for the material.

\section{MECHANICAL DAMAGE SIMULATION OF BUILDING REFRACTORIES}

Unlike ordinary materials, refractories have complex microstructures, for which traditional strength theory and life prediction cannot realize the accurate explanation and prediction [10]. The application of meso-mechanics can simulate the nonlinear mechanical behaviour of building refractories. The refractory materials commonly used in tall buildings are heterogeneous multiphase materials, generally composed of inorganic aggregates, binder phases and additives; the internal principal crystalline phase has a higher melting point and a certain thermal insulation effect [11]. By analysing the microstructure of building refractories, the mechanical properties and damage mechanisms of the materials can be established to predict the macroscopic properties of the refractory materials [12]. Park et al. [13] used different building refractories (Table 1) in the study and found that their mechanical properties differ greatly for the refractories with different chemical compositions.

Refractories are different from other building materials mainly in terms of their matrix phase, and their fracture characteristics don't conform to the linear elastic mechanical properties. When the refractory material is subjected to tensile load, the bond strength between the aggregate and the matrix inside the building material is weakened, and the phase separation phenomenon occurs, which will greatly reduce the overall rigidity of the material; when the refractory material is pressed, with the compressive stress increasing, microcracks are generated in the matrix phase, and microcrack propagation leads to material failure. Figure 1 shows the variation curve of the RWFR elastic modulus with the stress. Under the growing 
stress, the post-damage elastic modulus of the material decreases, mainly resulted from the brittle properties of the material.

The interfacial bond strength and particle strength of the refractory are greater than the matrix phase strength. The damage process of the refractory material at normal temperature is divided into three stages: initial damage, matrix damage and material damage. In this experiment, the refractories were compressed and loaded at room temperature, $300{ }^{\circ} \mathrm{C}$ and $600{ }^{\circ} \mathrm{C}$ respectively. The stress-strain relationship of the refractory at $300{ }^{\circ} \mathrm{C}$ and $600{ }^{\circ} \mathrm{C}$ is expressed as:

$300^{\circ} \mathrm{C}$ :

$\sigma=1.369 \times 10^{11} \varepsilon^{4}+1.2387 \times 10^{9} \varepsilon^{3}+3.4260 \times 10^{6} \varepsilon^{2}+8.2359 \times 1$ $0^{3} \varepsilon-14.63$

$600^{\circ} \mathrm{C}$ :

$\sigma=4.591 \times 10^{10} \varepsilon^{4}+5.618 \times 10^{8} \varepsilon^{3}+1.032 \times 10^{6} \varepsilon^{2}+5.269 \times 10^{3} \varepsilon$ $-33.12$

The Young's modulus-strain relationship is calculated as:

$300^{\circ} \mathrm{C}$ :

$$
\mathrm{E}=5.623 \times 10^{8} \varepsilon^{3}+3.5677 \times 10^{6} \varepsilon^{2}+6.5914 \times 10^{3} \varepsilon+9.688
$$

$600^{\circ} \mathrm{C}$ :

$$
\mathrm{E}=3.6289 \times 10^{8} \varepsilon^{3}+1.7922 \times 10^{6} \varepsilon^{2}+3.568 \times 10^{3} \varepsilon+4.92
$$

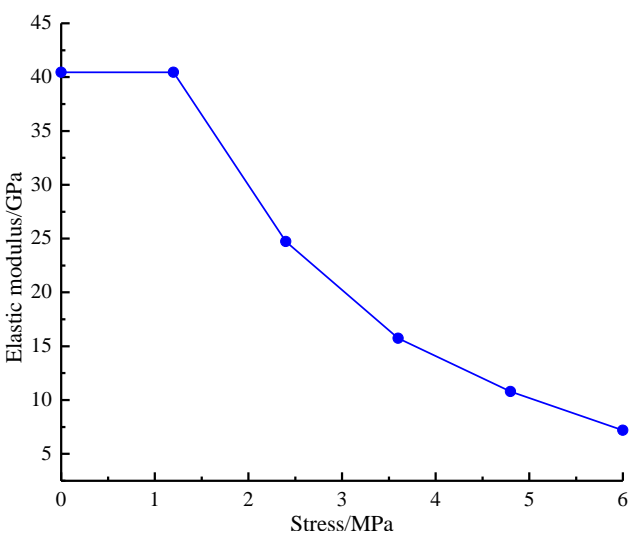

(a) Tension process

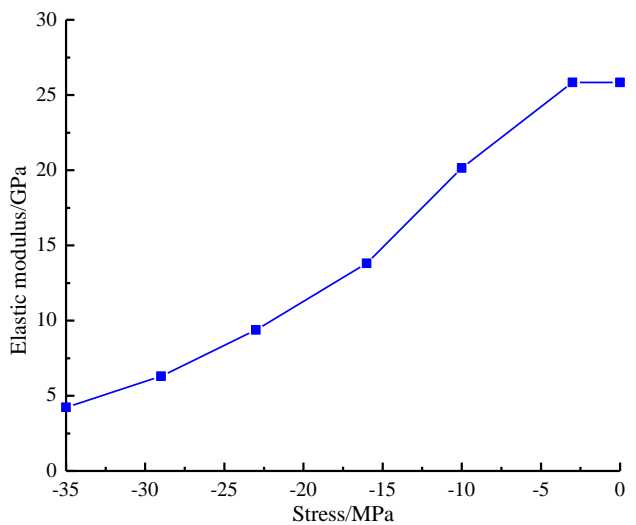

(b) Pressure process

Figure 1. Material elastic modulus with stress curve

Figure 2 shows the Young's modulus strain curve under high temperature compression. As the temperature increases, the Young's modulus of refractory decreases; the higher the temperature, the smaller the variation range of initial Young's modulus and the less reduction Young's modulus.

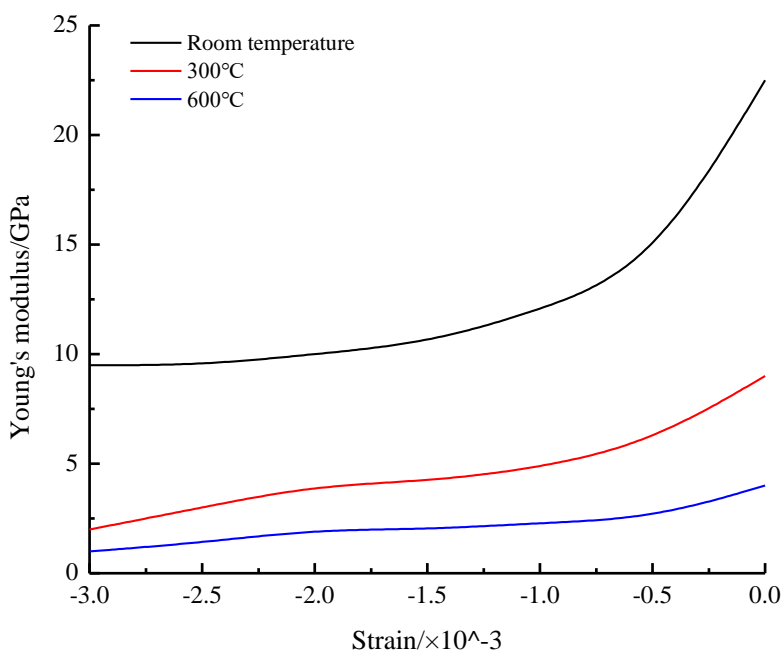

Figure 2. Young's modulus strain curve under high temperature compression

Table 1. Chemical composition and elastic modulus of two building refractories

\begin{tabular}{cccccccc}
\hline Materials & $\mathrm{MgO}$ & $\mathrm{C}$ & $\mathrm{Fe}_{2} \mathrm{O}_{3}$ & $\mathrm{SiO}_{2}$ & $\mathrm{CaO}$ & $\mathrm{Al}$ & Elastic modulus/GPa \\
\hline Materials A & 78.3 & 15.1 & 0.2 & 0.7 & 1.2 & 1.1 & 21.7 \\
Materials B & 90.3 & 6.7 & 0.2 & 0.1 & 2.7 & - & 89.1 \\
\hline
\end{tabular}

\section{CHARACTERIZATION METHOD OF MESO- DAMAGE TEST FOR TALL BUILDING REFRACTORY}

\subsection{Mechanical properties test}

At present, the refractory for tall buildings is mainly rock wool fibre material, which is composed of rock wool fibre and mortar to isolate and protect concrete. In order to study the mechanical properties of this material, the rock wool fibre mortar was prepared by mixing $35 \%$ rock wool fibre into the mortar. The $100 \mathrm{~mm} * 100 \mathrm{~mm} * 400 \mathrm{~mm}$ sample was cured in the standard curing room for $28 \mathrm{~d}$. Three point bending mechanical test was adopted. The flexural strength and flexural modulus are expressed as:

$$
\begin{aligned}
& \mathrm{F}=1.5 \times \frac{\Delta F \times 100}{b \times h^{3}} \\
& \mathrm{E}=\frac{\Delta F \times \mathrm{L}}{b \times h \times \delta}
\end{aligned}
$$

The apparent porosity and bulk density of the RWFR were measured by a tester. They are expressed as:

$$
\text { Apparent porosity: } \mathrm{P}=\frac{m_{3}-m_{1}}{m_{3}-m_{2}} \times 100 \%
$$




$$
\text { Bulk density: } \rho=\frac{m_{1} \rho_{w}}{m_{3}-m_{2}}
$$

where: $m_{1}, m_{2}$ and $m_{3}$ are the dry weight, the suspension weight, and the saturation weight of the samples, respectively, and $\rho_{\mathrm{w}}$ is the density of water.

Due to the incorporation of rock wool fibres, the mortar sample has a large porosity of $9.36 \%$ and a bulk density of $2.300 \mathrm{~g} / \mathrm{cm}^{3}$. Figure 3 shows the stress-strain curve of RWFR with the maximum stress of about $35 \mathrm{MPa}$ and the maximum strain of $4.5 \times 10^{-3}$.

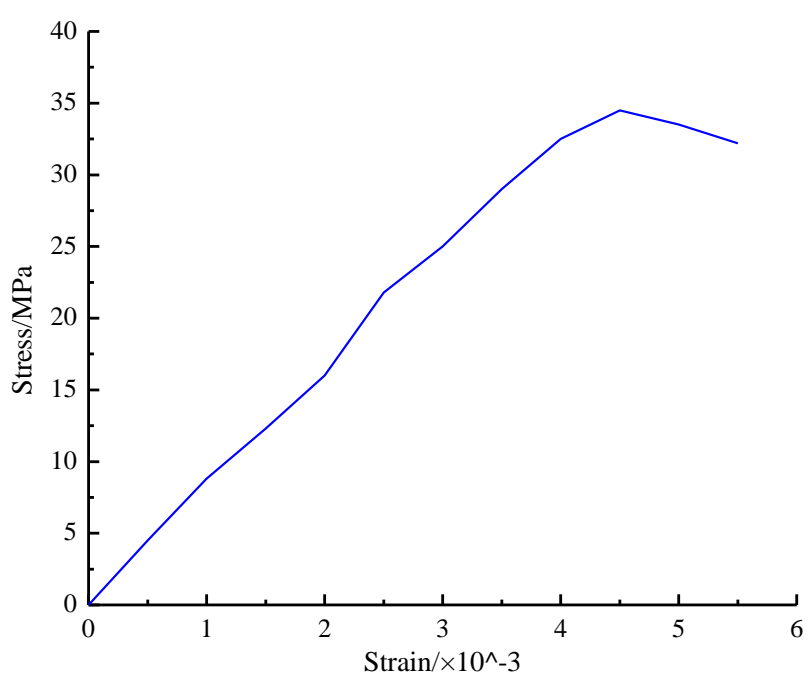

Figure 3. Stress-strain curve of rockwool mortar refractories

\subsection{High temperature test}

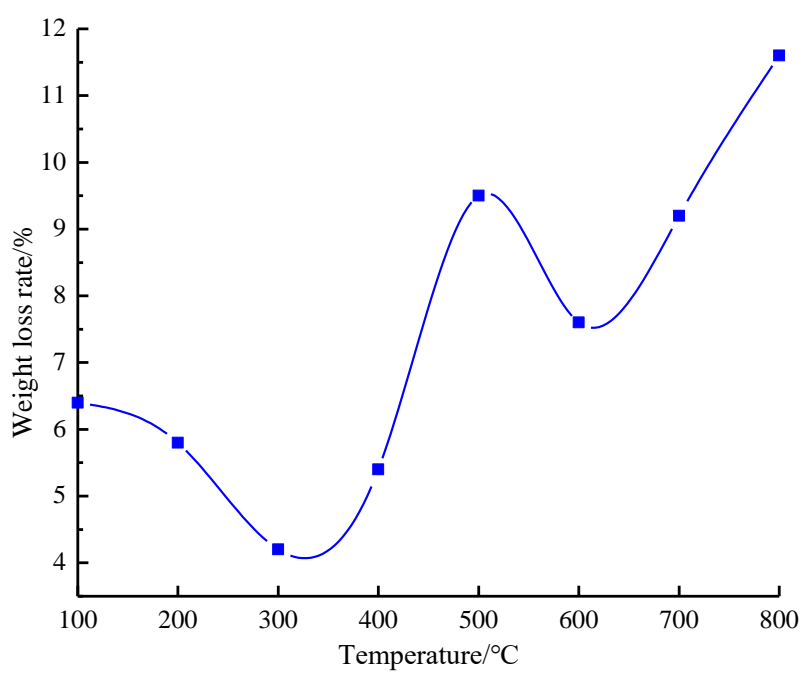

Figure 4. Test piece weight loss rate and temperature curve

For the high temperature test, the sample size was $100 \mathrm{~mm} * 100 \mathrm{~mm} * 100 \mathrm{~mm}$; the furnace temperature was controlled at $100{ }^{\circ} \mathrm{C}-800{ }^{\circ} \mathrm{C}$, and the temperature was increased progressively by $100{ }^{\circ} \mathrm{C}$. It was maintained in constant temperature for $60 \mathrm{~min}$ by muffle furnace. The average number of three samples was used as the test result. Figure 4 shows the relation curve between the weight loss rate of the sample and the temperature, indicating that the weight loss of the samples at different temperatures does not increase linearly, mainly due to different sources of water loss under different temperature conditions. At the earlier stage, mainly the free water and gel water had weight loss; when the temperature rose to $400{ }^{\circ} \mathrm{C}, \mathrm{Ca}(\mathrm{OH})_{2}$ dehydration occurred; when exceeding $600{ }^{\circ} \mathrm{C}$, the mass loss is mainly caused by the internal structure change of concrete. Figure 5 depicts the relationship between compressive strength and temperature of the samples. It can be seen that before $600{ }^{\circ} \mathrm{C}$, the compressive strength of the RWFR decreased less; when the temperature rose to $700{ }^{\circ} \mathrm{C}$, the strength declined to a large extent. The experiment indicates that the tested refractory material in this paper has better performance at $600{ }^{\circ} \mathrm{C}$.

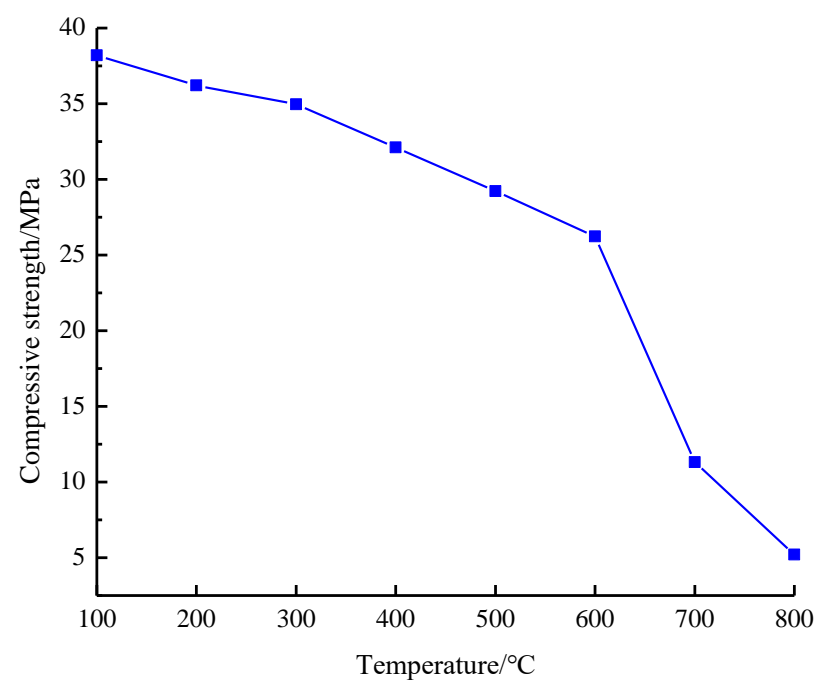

Figure 5. Test piece compressive strength and temperature curve

\subsection{Analysis of meso-damage test}

When the refractory material is loaded with external load, the acoustic emission can record the strain energy released during the occurrence and development of internal defects during the loading process. The damage position and development of the refractory mortar component can be clarified by means of acoustic emission technology. This test adopted a DiSP acoustic emission system with 16 acquisition channels which consists of three parts: sensor, amplifier and analysis system, to test the damage of the samples during the tri-axial loading process. In addition, the damage form of the RWFR is different, so it's necessary to characterize the compressed sample by the combination of time domain and frequency domain.

The acoustic emission signal obtained by the tri-axial loading needs to be classified using the wavelet energy spectrum coefficient. Assuming that $\mathrm{f}(\mathrm{t})$ is a wavelet transform function and $\psi(\mathrm{t})$ is a wavelet base, then the wavelet transform is expressed as:

$$
W_{f}(a, b)=\frac{1}{\sqrt{|a|}} \int_{-\infty}^{\infty} f(t) \psi\left(\frac{t-b}{a}\right) d t
$$

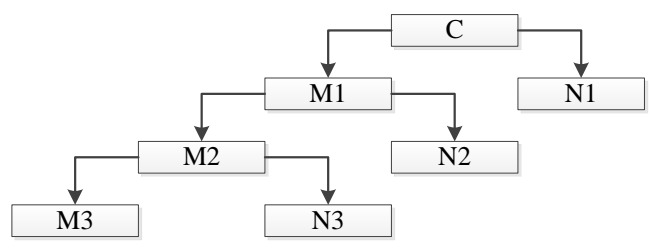

Figure 6. Wavelet transform decomposition structure diagram 
In the formula above, $\mathrm{a}$ and $\mathrm{b}$ represent the discretization coefficient. After the wavelet transform, the signal is decomposed into low-frequency approximation signal and the high-frequency detail signal, and the low-frequency signal is further decomposed to obtain the tree structure, as shown in Fig. 6. Figure 7 shows an acoustic emission energy-time history of the RWFR, indicating that the damage of the samples can be roughly divided into four stages: no damage stage, slow damage development stage, damage speeding development stage and damage failure stage.

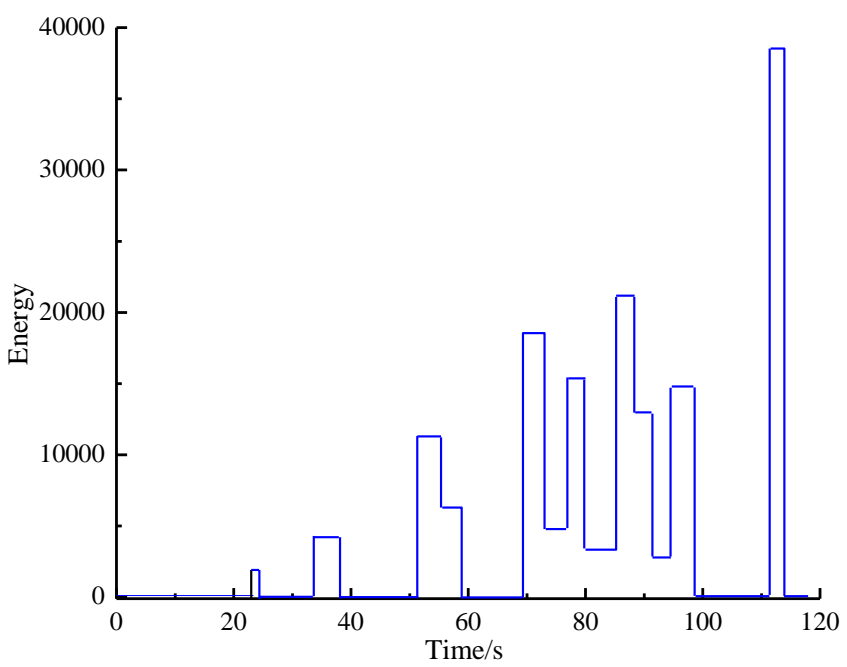

Figure 7. Acoustic emission energy-time history diagram of rock wool mortar refractory

\section{DAMAGE CONSTITUTIVE MODEL OF BUILDING REFRACTORY MATERIALS}

The damage of building refractory materials is manifested by the local damage of inelastic deformation. As the load increases, the inelastic deformation concentrates to the weak part of the material, while the other parts are in the elastic unloading stage. It can be seen from the damage evolution process that the damage process includes two parts: initial damage and damage evolution. At the initial damage stage, it's considered that the characteristic stress reaches the lowest strength of the internal phase in the refractory material; when entering the damage evolution stage, it's difficult to acquire the characteristic parameters of the samples, but easy for the energy parameter, which can be judged by the energy unloading relationship, as shown in Figure 8. According to this figure, the curve area represents the energy dissipation, and the value of the equivalent displacement at the end of the damage depends on the amount of energy dissipated; when the refractory is suddenly unloaded under the damaged state, the sample will recover along the OC route, but if the damage reoccurs, it will also develop along the OC route, with the damage retention function. The equivalent displacement of the initial damage is expressed as $\delta_{e q}^{m}$; at $\delta_{\mathrm{eq}} \geq \delta_{e q}^{0}$, the damage variable is defined as:

$$
\mathrm{d}=\frac{\delta_{\mathrm{eq}}}{\delta_{\mathrm{eq}}^{\mathrm{m}}-\delta_{\mathrm{eq}}^{0}}
$$

The characteristics of the RWFRs studied in this paper are greatly affected by the load properties. The triaxial loading test of the samples is approximated by the calculation of compression model. Based on the Abaqus finite element software, this paper applies the damage constitutive model to the RWFR for unit compression experiment. Figure 9 shows the comparison between the experimental results and analog values. It can be found that the analog value of the constitutive model has good consistency with the test values. Because of the tension process during the actual experiment, the peak stress strain of the analog value is greater than the test values.

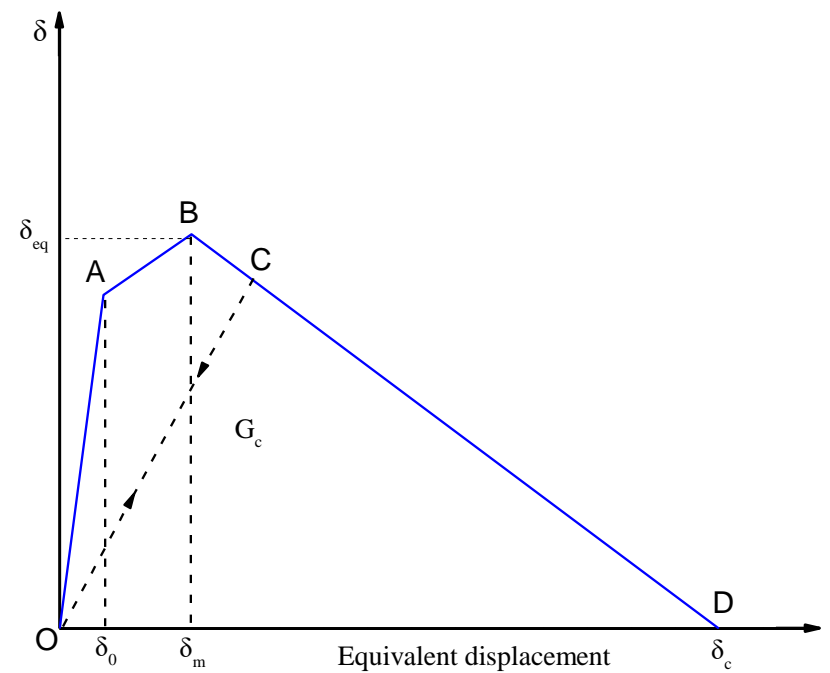

Figure 8. Energy-based unloading relationship

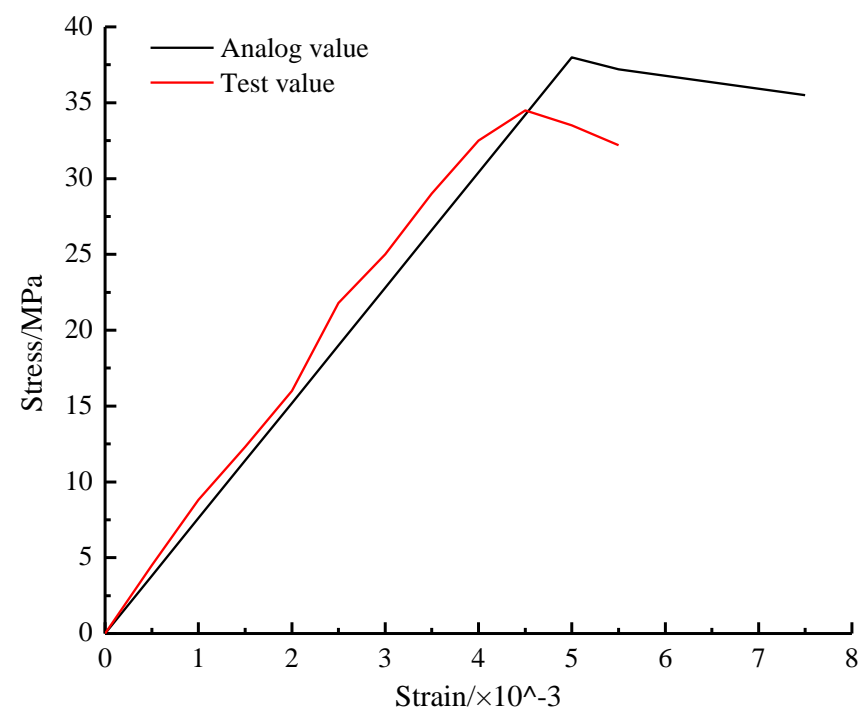

Figure 9. Comparison of experimental numerical results of refractory response

\section{CONCLUSIONS}

In this paper, the rock wool fibre was taken as an example of tall building refractories. On this basis, the author probed into the mechanical properties and damage evolution of the tall building refractory, and set up a meso-damage mechanics model for the material.

(1) As the temperature increases, the Young's modulus of refractory decreases; the higher the temperature, the smaller the variation range of initial Young's modulus and the less reduction Young's modulus. The maximum stress of the rock wool fibre refractory is about $35 \mathrm{MPa}$, and the maximum strain is $4.5 \times 10^{-3}$ 
(2) Before $600{ }^{\circ} \mathrm{C}$, the compressive strength of the RWFR material decreases little; when the temperature rises to $700{ }^{\circ} \mathrm{C}$, the strength decreases greatly, that is, the RWFR has a better performance at $600{ }^{\circ} \mathrm{C}$.

(3) The damage of the RWFR can be roughly divided into four stages: no damage stage, slow damage development stage, damage speeding development stage and damage failure stage. The damage process includes two parts: initial damage and damage evolution.

(4) The damage process of building refractory includes initial damage and damage evolution. The damage is manifested by the local damage of inelastic deformation; as the load increases, the inelastic deformation concentrates to the weak part of the material, while the other parts are in the elastic unloading stage.

\section{ACKNOWLEDGMENT}

Major Projects of the Natural Fund of Hefei University in 2018 (Item number: 18ZR02ZDA).

\section{REFERENCES}

[1] Chen, X., Yang, H., Sun, K. (2016). Developing a metamodel for sensitivity analyses and prediction of building performance for passively designed high-rise residential buildings. Applied Energy, 194: 422-439. https://doi.org/10.1016/j.apenergy.2016.08.180

[2] Lu, X., Zhou, B., Zhao, B., Lu, W. (2015). Shaking table test and numerical analysis of a high-rise building with steel reinforce concrete column and reinforce concrete core tube. The Structural Design of Tall and Special Buildings, 24(18): 1019-1037. https://doi.org/10.1002/tal.1224

[3] Shim, H.B., Kim, Y., Park, H.S. (2019). Experimental tests for improving buildability of construction methods for high-strength concrete columns in high-rise buildings. The Structural Design of Tall and Special Buildings, 28(2). https://doi.org/10.1002/tal.1570

[4] Chau, C.K., Xu, J.M., Leung, T.M., Ng, W.Y. (2016). Evaluation of the impacts of end-of-life management strategies for deconstruction of a high-rise concrete framed office building. Applied Energy, 185: 1593-1603. https://doi.org/10.1016/j.apenergy.2016.01.019
[5] Pejovic, J., Jankovic, S. (2016). Seismic fragility assessment for reinforced concrete high-rise buildings in southern euro-Mediterranean zone. Bulletin of Earthquake Engineering, 14(1): 185-212. https://doi.org/10.1007/s10518-015-9812-4

[6] Zhou, X., Li, G. (2013). A macro-element based practical model for seismic analysis of steel-concrete composite high-rise buildings. Engineering Structures, 49: 91-103. https://doi.org/10.1016/j.engstruct.2012.11.002

[7] Munir, A., Warnitchai, P. (2013). Optimal reduction of inelastic seismic demands in high-rise reinforced concrete core wall buildings using energy-dissipating devices. Structural Design of Tall and Special Buildings, 22(7): 543-568. https://doi.org/10.1002/tal.704

[8] Epackachi, S., Mirghaderi, R., Esmaili, O., Behbahani A.A.T., Vahdani, S. (2012). Seismic evaluation of a 56storey residential reinforced concrete high-rise building based on nonlinear dynamic time-history analyses. The Structural Design of Tall and Special Buildings, 21(4): 233-248. https://doi.org/10.1002/tal.586

[9] Warnitchai, P., Munir, A. (2011). Identification of reasons for high inelastic seismic demands in high rise RC core wall buildings. Procedia Engineering, 14(3): 1359-1366. https://doi.org/10.1016/j.proeng.2011.07.171

[10] Koduru, S.D., Haukaas, T. (2010). Probabilistic seismic loss assessment of a Vancouver high-rise building. Journal of Structural Engineering, 136(3): 235-245. https://doi.org/10.1061/(ASCE)ST.1943-541X.0000099

[11] Zou, D., Liu, T., Teng, J., Du, C., Li, B. (2014). Influence of creep and drying shrinkage of reinforced concrete shear walls on the axial shortening of high-rise buildings. Construction \& Building Materials, 55(2): 46-56. https://doi.org/10.1016/j.conbuildmat.2014.01.034

[12] Shin, M., Kang, H.K., Lafave, J.M., Grossman, J.S. (2012). Design and behaviour of a reinforced concrete high-rise tube building with belt walls. Structural Design of Tall and Special Buildings, 21(12): 918-932. https://doi.org/10.1002/tal.661

[13] Park, H.S., Won, J.H., Chung, W.J. (2019). Wind resistance performance evaluation of cable-type curtain wall system on reinforced concrete high-rise buildings. International Journal of Concrete Structures and Materials, 12(1): 1-11. https://doi.org/10.1186/s40069018-0320-1 